\title{
Trainees' experience of organising their training
}

\author{
Pauline McConville and Arturo Langa
}

\begin{abstract}
Little has been published by trainees of their involvement in the organisation of their academic curiculum. This articte discusses the experience of two trainee representatives to the Post Graduate Training Committoe (PGTC) in Flfe with particular regard to three areas (academic programme, general assesement and exam preparation) over a one year period.
\end{abstract}

The need for trainee psychiatrists to be represented on committees responsible for the organisation of training within a scheme has long been recognised, and advocated by the Royal College of Psychiatrists in their requirements for approval of training schemes (1989a). In a call for a trainees' charter, Davies (1993) reinforced the importance of trainee participation in the training committee and suggested they participate in allocation meetings. The Fife rotation offers placements for psychiatric training to six senior house officers (SHOs) and four registrars. Four SHO GP trainees are offered six month placements in acute psychiatry and two senior registrars rotate through the region. The postgraduate training committee (PGTC) comprises the clinical tutor, two consultant advisers, specialist tutors in child and family psychiatry, learning disability and psychotherapy, four trainees representatives, currently an SHO, two registrars and a senior registrar, and a staff grade psychiatrist, representing non training grades.

The committee meets every four weeks, is chaired by the clinical tutor and invites other representatives, responsible for related matters such as the medical library when required.

The committee's responsibilities include the formal teaching programme, assessment of the trainees, ensuring appropriate experience and supervision is available in each placement. facilitation of trainees' wider interests such as research and audit projects, trainees preparation for professional examinations, overall responsibility for teaching, training and supervision.

\section{The formal teaching}

The academic curriculum is organised into three terms and the majority of meetings are devoted to case presentation, providing experience for the development of presentation skills. Cases are selected by the supervising consultant and presented by the trainee who may also present related literature.

Several sessions per term are reserved for lectures on specialised topics from speakers outside the service. This curriculum is outlined for each term by the PGTC and organised by one of the trainees under the supervision of the clinical tutor before being finalised by the committee. Another trainee complles the programme for a weekly journal club, the second part of the weekly academic programme, papers being assigned from recommended reading lists from the Royal College of Psychiatrists and current literature. Links have been established with the local area research network which provides advice, support and some resources and may help to overcome some pitfalls in research (Atkinson \& Cola, 1993).

A less formal weekly meeting was set up at each hospital site involving non-training grades such as staff psychiatrists and clinical assistants as well as pharmacists and psychologists for regular presentations of cases, book reviews, ethical discussions and service provision issues.

\section{Assessment of trainees and placements}

Discussion of an individual's progress is kept to a minium number of people and confidentiality respected. Particular needs of a trainee can then be addressed by the tutor and supervising consultant and the trainee's previous progress taken into account when deciding on placement allocation. This is proposed by the tutor after discussion with all trainees at which career progression and service requirements can be balanced, and finalised by the committee. Meetings between the clinical tutor and each trainee take place every six months to discuss overall progress.

The PGTC carries out ongoing evaluation of the placements by a questionnaire circulated at the end of each placement. The benefits of auditing of 
trainees' satisfaction with their training has been reported on by Cunningham (1933). The committee identified as areas of inquiry overall workload, type of caseload, proportion of primary care responsibility, supervision arrangements and opportunity for community work.

One problem area in several of the placements, identified in the initial questionnaire, was trainees' over-involvement in regular primary care and duty doctor responsibilities.

\section{Ixam preparation}

Adequate preparation for the MRCPsych examination is an almost constant source of concern for the trainee and often requires greater emphasis within training schemes.

The training committee sees preparation as an important experience to offer the trainee, and a system of regular mock exams, mimicking the MRCPsych examinations, has been implemented. As candidates approach the exam a series of mock clinical and patient management vivas can be arranged by the clinical tutor.

\section{Experience of trainee members of the committee}

The involvement of trainees with the training committee is a valuable vehicle for direct audit and managerial training experience and is called for by the College in its statement on approval of training schemes $(1989 \mathrm{~b}$ section 111,9$)$. Effort is made to ensure that the view taken back to the training committee is representative of the total body of junior staff. Regular discussion of training issues is provided for by training being a regular agenda item for junior staff meetings, which promotes interest in the work of the committee, generates ideas and gives the trainees a clear structure for raising issues they feel ought to be addressed.

To clarify the situation so far as training issues were concerned, the committee undertook an audit of trainees' satisfaction with their most recently completed placement. This was designed by one of the trainees and, after amendment by the PGTC, was circulated. A response rate of $100 \%$ was achieved, providing comprehensive data on all posts. The local knowledge afforded to the committee by the trainees allowed improvements in posts to be easily implemented through liaison with medical and non medical staff on each site.
The value of the process was recognised and the audit will be repeated annually. The results will be used by the training committee (taking into account national standards) to implement appropriate change.

\section{Conclusions}

Participation of trainee psychiatrists in the organisation of their training is beneficial for a number of reasons but principally because it allows the workings of the committee to be more user-friendly to the trainee. We would suggest that trainees participate in training committees in a structured manner which allows:

(a) adequate numbers of trainee representatives on the committee so that the various training grades can be properly represented

(b)a process for assessment of the trainee and evaluation of the placements to be decided in consultation with trainees

(c) formal feedback to the junior staff committee, and ease of access of the trainee's opinion to the training committee

(d)direct involvement in drawing up academic teaching programmes.

The responsibilities of a training committee are various and this account is by no means a comprehensive analysis of all the work of the PGTC within Fife. Rather, it gives an idea of how trainees can benefit from being involved in organising their own training, in a forum where their participation is welcomed and they are regarded as valuable.

\section{References}

Atkinson, J.M. \& ColA, D.A. (1993) Trainees and research. Psychiatric Bulletin, 17, 355-356.

Cunningham, S. (1993) Trainees and research. Psychiatric Bulletin, 17, 93-94.

Davies, S. (1993) Time for a trainees' charter? Psychiatric Bulletin, 17, 229-230.

ROYAL COLLEGE OF PSYCHIATRISTS (1989a) Statement of Training Schemes for General Professional Training for the MRCPsych.

- (1989b) Recognition of Psychiatric Tutors and Others Concerned with the Provision of Postgraduate Psychititic Education and Training.

Pauline McConville, Registrar, Lynebank Hospttal; *Arturo Langa, Senior Registrar, Lynebank Hospital, Halbeath Road, Dunfermline KY11 4UW

*Correspondence 